\title{
PENDAPATAN DAN KELAYAKAN USAHATANI BAWANG MERAH (Studi Kasus di Desa Tangru Kecamatan Malua Kabupaten Enrekang)
}

\author{
INCOME AND FEASIBILITY OF ONION BUSINESS \\ (Case Study in Tangru Village Malua District Enrekang Regency)
}

\author{
Muhammad Arifin Fattah, Sri Mardiyati \\ ProdiAgribisnis, FakultasPertanian, Universitas Muhammadiyah Makassar \\ Jl. Sultan Alauddin No. 259 Makassar \\ E-mail: arifinfattah@unismuh.ac.id \\ (Diterima 19-12-2021; Disetujui 22-01-2022)
}

\begin{abstract}
ABSTRAK
Bawang merah adalah tanaman hortikulutra dari komoditi sayuran yang telah lama diusahakan oleh petani secara intensif. Komoditi ini merupakan sumber pendapatan dan kesempatan kerja yang memberikan kontribusi cukup tinggi terhadap perkembangan ekonomi wilayah. Permintaan dan kebutuhan konsumsi bawang merah yang tinggi menjadikan komoditas ini menguntungkan jika diusahakan. Tujuan penelitian ini adalah menganalisis pendapatan dan kelayakan usahatani bawang merah di Desa Tangru Kecamatan Malua Kabupaten Enrekang. Penelitian ini dilakukan di Desa Tangru Kecamatan Malua Kabupaten Enrekang. Populasi penelitian ini adalah petani bawang merah yang berjumlah 319 orang. Jumlah sampel dalam penelitian ini adalah 10\% dari jumlah populasi yaitu sebanyak 31 petani. Sampel petani diambil menggunakan metode simple random sampling. Teknik pengumpulan data yang digunakan dalam penelitian ini adalah pengamatan/observasi, wawancara, dan dokumentasi. Jenis data dalam penelitian ini adalah data kualitatif dan data kuantitatif. Sumber data yaitu data primer dan sekunder. Metode analisis data yang digunakan dalam penelitian ini adalah deskriptif kuantitatif. Hasil penelitian ini menunjukkan pendapatan rata-rata yang diterima oleh petani usahatani bawang merah di Desa Tangru Kecamatan Malua Kabupaten Enrekang sebesar Rp78.482.900,00/MT. Usahatani bawang merah yang dilakukan oleh petani bawang merah layak diusahakan.
\end{abstract}

Kata Kunci: Pendapatan, Kelayakan, BawangMerah

\begin{abstract}
Shallots are horticulture crops that are derived from vegetable commodities that have been intensively farmed for a long period by farmers. This commodity is a source of income and job opportunities that makes a significant contribution to regional economic growth. Shallots are a profitable item to cultivate because of their high demand and requirement for consumption. The goal of this research was to determine the profitability and viability of onion cultivation in Tangru Village, Malua District, Enrekang Regency. Tangru Village, Malua District, Enrekang Regency was the site of this study. The population of this study consisted of 319 shallot farmers. In this study, the number of samples was 10\% of the overall population, or 31 farmers. Simple random sampling was used to collect samples from farmers. Data collection techniques used in this study were observation, interviews, and documentation. The types of data in this study are qualitative data and quantitative data. Data sources are primary and secondary data. The data analysis method used in this research is descriptive quantitative. The results of this study indicate that the average income received by shallot farmers in Tangru Village, Malua District, Enrekang Regency is Rp78.482.900.00/MT. Shallot farming carried out by shallot farmers is feasible.
\end{abstract}

Keywords: Income, Eligibility, Shallot 


\section{PENDAHULUAN}

Kegiatan pokok dan sumber pendapatan utama masyarakat khususnya masyarakat di pedesaan, masih tergantung pada sektor pertanian. Dapat diartikan bahwa kehidupan sebagian besar rumah tangga tergantung pada sektor pertanian (Arifin dkk, 2021). Pengembangan komoditas usahatani bernilai tinggi guna meningkatkan pendapatan petani merupakan hal penting dalam meningkatkan kemampuan sektor pertanian. Kemampuan sektor pertanian untuk memberikan kontribusi secara langsung terhadap pertumbuhan ekonomi dan kesejahteraan rumah tangga tani tergantung pada tingkat pendapatan usahatani dan surplus yang dihasilkan oleh sektor itu sendiri. Komoditas hortikultura merupakan komoditas potensial yang mempunyai nilai ekonomi tinggi dan memiliki potensi untuk terus dikembangkan. Pengembangan usahatani dengan komoditas hortikultura bernilai tinggi diantaranya dengan mengembangkan usahatani bawang merah untuk meningkatkan pendapatan petani (Lawalata dkk, 2017).

Bawang merah merupakan salah satu komoditi sayuran yang memiliki nilai ekonomi tinggi ditinjau dari sisi pemenuhan konsumsi nasional, sumber penghasilan petani, dan potensinya sebagai penghasil devisa negara (Baharuddin dan Muhammad, 2021; Swastika dkk, 2017; Sadaruddin dkk, 2017). Kebutuhan masyarakat terhadap bawang merah dari tahun ke tahun mengalami peningkatan seiring dengan pertambahan jumlah penduduk dan daya beli masyarakat yang cenderung naik. Dengan demikian, agar kebutuhan dapat terpenuhi, maka harus diimbangi dengan jumlah produksi. Besar kecilnya jumlah produksi dipengaruhi oleh berbagai macam faktor seperti luas lahan, bibit, pupuk, pestisida, sistem irigasi, tenaga kerja, iklim dan sebagainya (Dahlianawati dkk, 2020).

Bawang merah adalah tanaman hortikulutra dari komoditi sayuran yang telah lama diusahakan oleh petani secara intensif (Gumilar dkk, 2019). Komoditi ini merupakan sumber pendapatan dan kesempatan kerja yang memberikan kontribusi cukup tinggi terhadap perkembangan ekonomi wilayah (Sadaruddin dkk, 2017). Tingkat konsumsi bawang merah penduduk Indonesia mencapai $4,56 \mathrm{~kg} / \mathrm{kapita} / \mathrm{tahun}$. Permintaan dan kebutuhan konsumsi bawang merah yang tinggi menjadikan komoditas ini menguntungkan jika diusahakan. Tingginya permintaan 
bawang merah yang terus meningkat tidak hanya terjadi di pasar dalam negeri, tetapi berpeluang juga untuk ekspor (Herlita dkk, 2016).

Bawang merah merupakan komoditas yang mempunyai kemampuan menaikkan tingkat pendapatan petani, sebagai bahan baku hampir semua industri makanan, dibutuhkan setiap saat sebagai bumbu masak, obat tradisional, berpeluang ekspor dan dapat membuka kesempatan kerja. Bawang merah memiliki kelemahan dalam pengembangan ekspor, namun memiliki tren produksi yang cukup baik. Konsumsi berbagai jenis komoditas hortikultura dalam negeri masih relatif tinggi dibandingkan tingkat produksi yang dicapai dan diperkirakan akan terus meningkat. Sedangkan di Indonesia hanya sedikit petani yang membudidayakan bawang merah tersebut (Nasution dan Rosmawati, 2018).

Usahatani bawang merah di Kabupaten Enrekang telah lama dibudidayakan petani dengan luasan yang terbatas. Untuk Kecamatan Malua luas areal tanaman bawang merah yaitu sebesar 910 ha dengan produksi 215,4 ton (BPS Kabupaten Enrekang, 2020). Kontribusi sektor pertanian tanaman hortikultura khususnya bawang merah di
Kabupaten Enrekang cukup besar, tetapi belum dinikmati secara adil oleh petani. Hal ini disebabkan 60 persen dinikmati pedagang, sedangkan petani hanya mendapatkan $40 \%$. Idealnya petani yang harus mendapatkan porsi lebih besar karena risiko yang diterima petani lebih besar. Pemerintah Kabupaten Enrekang menetapkan harga yang layak bagi petani dengan menetapkan harga dasar bawang merah dan akan membeli produk petani di saat harga di bawah harga yang telah ditetapkan. Kebijakan ini untuk melindungi petani sehingga petani bawang merah dapat memperoleh keuntungan dari usahataninya dan dapat berkelanjutan. Peningkatan produksi dan pendapatan petani tergantung pada perilaku petani dalam berusahatani. Dalam usahatani selalu bertujuan memperoleh pendapatan dan keuntungan yang tinggi (Sadaruddin dkk, 2017). Tujuan penelitian ini adalah menganalisis pendapatan dan kelayakan usahatani bawang merah di Desa Tangru Kecamatan Malua Kabupaten Enrekang.

\section{METODE PENELITIAN}

Penelitian ini dilakukan di Desa Tangru Kecamatan Malua Kabupaten Enrekang. Penelitian ini dilaksanakan pada bulan April - Mei 2021. Populasi 
penelitian ini adalah petani bawang merah di Desa Tangru Kecamatan Malua Kabupaten Enrekang yang berjumlah 319 orang. Jumlah sampel dalam penelitian ini adalah $10 \%$ dari jumlah populasi yaitu sebanyak 31 petani. Sampel petani diambil menggunakan metode simple random sampling.

Teknik pengumpulan data yang digunakan dalam penelitian ini adalah pengamatan/observasi, wawancara, dan dokumentasi. Jenis data dalam penelitian ini adalah data kualitatif dan data kuantitatif. Sedangkan sumber data adalah segala sesuatu yang memberikan informasi mengenai data berdasarkan sumbernya. Sumber data ada dua yaitu data primer dan sekunder.

Metode analisis data yang digunakan dalam penelitian ini adalah deskriptif kuantitatif. Untuk analisis pendapatan usahatani bawang merah digunakan rumus sebagai berikut.

$$
\begin{aligned}
& \pi=\mathrm{TR}-\mathrm{TC} \\
& \mathrm{TR}=\mathrm{P} . \mathrm{Q} \\
& \mathrm{TC}=\mathrm{VC}+\mathrm{FC}
\end{aligned}
$$

Keterangan :

$$
\begin{array}{ll}
\pi & \text { : Pendapatan (Rupiah) } \\
\text { TR } & : \text { Total Revenue (total penerimaan) } \\
& \text { (Rupiah) } \\
\text { TC } & \text { : Total Cost (total biaya) (Rupiah) } \\
\text { P } & \text { : Harga produk (Rupiah) }
\end{array}
$$

Q : Jumlah produksi ( $\mathrm{kg})$

VC : Variable Cost (biaya variabel) (Rupiah)

FC : Fixed Cost (biaya tetap) (Rupiah)

Untuk analisis kelayakan usahatani bawang merah digunakan rumus sebagai berikut.

$$
\mathrm{R} / \mathrm{C} \text { ratio }=\frac{\mathrm{TR}}{\mathrm{TC}}
$$

Kriteria untuk kelayakan :

1) $\mathrm{R} / \mathrm{C}>1$, artinya usahatani bawang merah yang dilakukan memperoleh keuntungan dan layak diusahakan.

2) $\mathrm{R} / \mathrm{C}=1$, artinya usahatani bawang merah tidak memperoleh keuntungan atau tidak mengalami kerugian (impas).

3) Jika R/C Ratio < 1, maka usahatani bawang merah mengalami kerugian atau tidak layak untuk diteruskan.

\section{HASIL DAN PEMBAHASAN}

\section{Analisis Pendapatan Usahatani Bawang Merah}

Analisis usahatani merupakan indikator dalam menentukan berapa besar biaya yang dikeluarkan meliputi biaya produksi, penerimaan dan pendapatan serta mengetahi R/C Ratio pada suatu usahatani (Marsaoly dkk, 2020). Suatu usaha dapat dikatakan mencapai keuntungan apabila total penerimaannya lebih besar dari pengeluarannya. Untuk 
mengetahui keuntungan yang diperoleh responden dari usahanya, maka perlu dilakukan perhitungan dengan cara menggunakan total penerimaan dengan total biaya yang dikeluarkan. Penerimaan merupakan hasil kali antara jumlah produksi dengan harga jual (Sugianto dkk, 2019).

Pendapatan atau keuntungan petani dapat diketahui dengan mengurangi penerimaan dengan total biaya yang dikeluarkan per musim tanam. Tingkat pendapatan usahatani bawang merah dihitung dengan menghitung biaya yang dikeluarkan pada usahatani bawang merah atau disebut juga biaya produksi (Nurhapsa dkk, 2015). Pendapatan bawang merah merupakan selisih antara penerimaan dengan total biaya yang dikeluarkan selama satu musim tanam, sedangkan keuntungan diperoleh dari selisih antara penerimaan dengan total biaya yang dikeluarkan selama satu musim tanam (Sinaga dkk, 2021). Besarnya pendapatan yang diperoleh petani responden dapat diketahui dengan terlebih dahulu menghitung besarnya tingkat penerimaan yang diperoleh serta biaya-biaya yang dikeluarkan pada suatu usahatani. Analisis pendapatan usahatani bawang merah di DesaTangru Kecamatan
Malua Kabupaten Enrekang dapat dilihat pada Tabel 1.

Tabel 1. Rata-rata Penerimaan, Biaya dan Pendapatan Usahatani Bawang Merah di Desa Tangru Kecamatan Malua Kabupaten Enrekang

\begin{tabular}{|c|c|c|}
\hline No. & Uraian & Nilai \\
\hline \multirow[t]{5}{*}{1.} & Penerimaan: & \\
\hline & Produksi rata-rata $(\mathrm{kg})$ & $7.126,67$ \\
\hline & Harga rata-rata $(\mathrm{Rp})$ & $15.166,67$ \\
\hline & Penerimaan rata-rata & \\
\hline & $(\mathbf{R p})$ & 108.275.000,00 \\
\hline \multirow[t]{18}{*}{2.} & BiayaVariabel (Rp): & \\
\hline & Bibit & $23.207 .500,00$ \\
\hline & Pupuk NPK & $471.333,00$ \\
\hline & Pupuk Nitrogen (N) & $112.500,00$ \\
\hline & Pupuk Kalium (K) & $491.667,00$ \\
\hline & Pupuk K2O & $421.333,00$ \\
\hline & Dangke (Metomil) & $75.000,00$ \\
\hline & Antracool (70 WP) & $272.000,00$ \\
\hline & Marsal 20 EC & $140.000,00$ \\
\hline & Capriotop (60 WG) & $196.296,00$ \\
\hline & Tenaga kerja (Rp): & \\
\hline & Pengolahan lahan & $773.333,00$ \\
\hline & Penanaman & $843.333,00$ \\
\hline & Pemeliharaan & $873.333,00$ \\
\hline & Panen & $933.333,00$ \\
\hline & Pascapanen & $510.000,00$ \\
\hline & Jumlah Biaya Variabel & \\
\hline & $(\mathbf{R p})$ & $29.320 .961,00$ \\
\hline \multirow[t]{9}{*}{3.} & BiayaTetap (Rp): & \\
\hline & Penyusutan alat: & \\
\hline & Sabit & $8.256,00$ \\
\hline & Cangkul & $15.683,00$ \\
\hline & Pompa air & $143.333,00$ \\
\hline & Pipa & $282.667,00$ \\
\hline & Pajaklahan & $21.200,00$ \\
\hline & JumlahBiayaTetap & \\
\hline & (Rp) & 471.139,00 \\
\hline 4. & $\begin{array}{l}\text { Total Biaya (Rp): } \\
(2+3)\end{array}$ & $29.792 .100,00$ \\
\hline 5. & Pendapatan (Rp) & $78.482 .900,00$ \\
\hline
\end{tabular}

Berdasarkan Tabel 1 analisis pendapatan dalam penelitian ini ditujukan untuk mengetahui besarnya pendapatan petani responden pada usahatani bawang merah di Desa Tangru Kecamatan Malua Kabupaten Enrekang selama satu kali musim panen, dengan cara menghitung 
selisih antara total penerimaan dan total biaya yang dikeluarkan dalam satu siklus pembudidayaan.

Usaha dikatakan mencapai keuntungan apabila total penerimaannya lebih besar dari pengeluarannya. Untuk mengetahui keuntungan yang diperoleh dari suatu usaha, maka perlu dilakukan perhitungan dengan cara menggunakan total penerimaan dengan total biaya yang dikeluarkan. Penerimaan merupakan hasil kali antara jumlah produksi dengan harga jual (Sugianto dkk, 2019). Penerimaan dalam penelitian ini merupakan hasil perkalian antara jumlah produksi rata-rata yang diperoleh dengan harga jual ratarata di tingkat petani. Produksi rata-rata bawang merah sebesar 7.126,67 kg dikalikan dengan harga jual rata-rata di tingkat petani sebesar Rp15.166,67. Dengan demikian, penerimaan rata-rata yang diperoleh yaitu sebesar Rp108.275.000,00.

Biaya merupakan semua pengorbanan yang perlu dilakukan untuk proses produksi, yang dinyatakan dengan satuan uang menurut harga pasar yang berlaku, baik yang sudah terjadi maupun yang akan terjadi. Biaya produksi dalam usahatani bawang merah merupakan semua pengeluaran yang diperlukan petani bawang merah, baik yang bersifat tunai maupun non tunai, untuk menghasilkan produksi dalam satu kali musim tanam (Marsaoly dkk, 2020). Biaya produksi bawang merah dapat digolongkan atas dasar hubungan perubahan volume produksi, yaitu biaya tetap dan biaya variabel. Termasuk dalam biaya tetap adalah biaya penyusutan alat dan biaya lain-lain, sedangkan biaya variabel adalah biaya bibit, biaya pupuk, biaya pestisida, dan biaya tenaga kerja. Penjumlahan kedua biaya tersebut menghasilkan biaya total dalam satu kali musim tanam (Mar'uf dkk, 2019).

Kegiatan usahatani bawang merah di Desa Tangru Kecamatan Malua Kabupaten Enrekang selama satu kali musim panen untuk menghasilkan produksi telah mengeluarkan biaya, yaitu biaya variabel dan biaya tetap. Biaya variabel adalah biaya yang besar kecilnya mempengaruhi produksi yang dihasilkan. Untuk biaya variabel dalam penelitian ini adalah biaya bibit, pupuk, obat-obatan, dan tenaga kerja. Rata-rata biaya variabel yang dikeluarkan adalah sebesar Rp29.320.961,00. Sedangkan biaya tetap tidak berpengaruh langsung terhadap besar kecilnya produksi yang diperoleh. Untuk biaya tetap dalam penelitian ini adalah penyusutan alat dan pajak lahan. Rata-rata biaya tetap yang dikeluarkan 
adalah sebesar Rp471.139,00. Dengan demikian, total biaya yang digunakan sebesar Rp29.792.100,00.

Pendapatan petani bawang merah merupakan hasil pengurangan dari penerimaan yang diterima oleh petani bawang merah dengan besarnya biaya total yang dikeluarkan. Secara umum, peningkatan produksi suatu usahatani merupakan indikator keberhasilan dari usahatani yang bersangkutan. Namun, tingginya produksi suatu komoditas yang diperoleh dalam per satuan luas lahan belum menjamin tingginya pendapatan usahatani bawang merah yang dipengaruhi oleh harga yang diterima petani dan biaya-biaya penggunaan input (Mar'uf dkk, 2019). Dalam penelitian ini pendapatan rata-rata yang diterima oleh petani bawang merah di Desa Tangru Kecamatan Malua Kabupaten Enrekang sebesar Rp78.482.900,00/MT.

\section{Kelayakan Usahatani Padi Sawah Tadah Hujan}

Untuk melakukan analisis kelayakan usahatani padi, digunakan analisis Revenue-Cost Ratio (R/CRatio). Analisis ini merupakan rasio dari penerimaan usahatani dengan total biaya usahatani (Mawardi dkk, 2020). RevenueCost ratio $(\mathrm{R} / \mathrm{C})$ merupakan salah satu indikator yang dapat digunakan untuk mengetahui kelayakan suatu usaha. Analisis $\mathrm{R} / \mathrm{C}$ ratio dihitung dengan membandingkan antara penerimaan (revenue) dengan biaya total (Mar'uf dkk, 2019). Nilai R/C pada usahatani bawang merah di Desa Tangru Kecamatan Malua Kabupaten Enrekang dapat dilihat pada Tabel 2.

Tabel 2. Nilai R/C Ratio Bawang Merah di Desa Tangru Kecamatan Malua Kabupaten Enrekang

\begin{tabular}{clr}
\hline No. & \multicolumn{1}{c}{ Uraian } & \multicolumn{1}{c}{ Nilai } \\
\hline 1. & $\begin{array}{l}\text { Penerimaan }(\mathrm{R}) \\
(\mathrm{Rp})\end{array}$ & $108.275 .000,00$ \\
\hline 2. & Biaya (C) $(\mathrm{Rp})$ & $29.792 .100,00$ \\
\hline 3. & R/C ratio & 3,63 \\
\hline \multicolumn{2}{l}{ Sumber : Analisis Data Primer $(2021)$}
\end{tabular}

Berdasarkan Tabel 2 diketahui bahwa $\mathrm{R} / \mathrm{C}$ ratio $>1$. Hal ini menunjukkan bahwa setiap pengeluaran biaya Rp1,00 maka akan diperoleh penerimaan sebesar Rp3,63. Dengan hasil kelayakan yang diperoleh dari usahatani bawang merah yang dilakukan oleh petani di Desa Tangru Kecamatan Malua Kabupaten Enrekang layak untuk diusahakan.

\section{KESIMPULAN DAN SARAN}

\section{Kesimpulan}

Berdasarkan hasil penelitian maka dapat disimpulkan pendapatan rata-rata yang diterima oleh petani pada usahatani bawang merah di Desa Tangru Kecamatan Malua Kabupaten Enrekang 
sebesar Rp78.482.900,00/MT. Usahatani bawang merah yang dilakukan oleh petani di Desa Tangru Kecamatan Malua Kabupaten Enrekang layak untuk diusahakan.

\section{Saran}

Untuk pemangku kepentingan dalam hal ini pemerintah daerah disarankan melakukan pendidikan non formal atau penyuluhan kepada petani dalam hal penggunaan inovasi teknologi perbenihan dan penggunaan benih yang berkualitas. Diharapkan petani bawang merah dapat meningkatkan skala usahatani menjadi lebih besar sehingga tingkat pendapatan yang diperoleh semakin tinggi

\section{DAFTAR PUSTAKA}

Arifin, Biba, MA., dan Syafiuddin, 2021.The Contribution of Rainfed Rice Farming to Income and Food Security of Farmers' Household. Journal of Socioeconomics and Development, 4(2), 180-188.

Baharuddin, L., dan Muhammad, M., 2021. Analisis Pendapatan dan Tingkat Kesejahteraan Petani Bawang Merah Lokal Topo di Kelurahan Afa-Afa Kecamatan Tidore Utara Kota Tidore Kepulauan. Jurnal Biosainstek, 3(1), 46-52.

BPS Enrekang. (2020). Kabupaten Enrekang dalam Angka 2020. Badan Pusat Statistik Kabupaten Enrekang.
Dahlianawati, Sofyan, dan Jakfar, F., 2020. Analisis Pendapatan Usahatani Bawang Merah (Allium ascalonicum L) di Kecamatan Banda Baro Kabupaten Aceh Utara. Jurnal Ilmiah Mahasiswa Pertanian, 5(4), 31-44.

Gumilar, AS., Hidayat, YR., dan Sukanata, IK., 2019. Analisis Komparasi Biaya dan Pendapatan Usaha Tani Bawang Merah Dataran Tinggi Antara Sistem Pengolahaan Tanah Cultivator Dengan Sistem Konvensional (Kasus di Desa Sukasari Kaler Kecamatan Argapura Kabupaten Majalengka). Paradigma Agribisnis, 2(2), 13-21.

Herlita, M., Tety, E., dan Khaswarina, S., 2016. Analisis Pendapatan Usahatani Bawang Merah (allium ascalonicum) di Desa Sei Geringging Kecamatan Kampar Kiri Kabupaten Kampar. Jurnal On Line Mahasiswa Faperta, 3(1), 112.

Lawalata, M., Darwanto, DJ., dan Hartono, S., 2017. Risiko Usahatani Bawang Merah di Kabupaten Bantul. Agrica (Jurnal Agribisnis Sumatera Utara), 10(1), 56-73.

Marsaoly, HA., Sangadji, SS., dan Sumartono, E., 2020. Analisis Profitabilitas Usaha Tani Bawang Merah pada Unit Transmigrasi (Trans Koli). Jurnal Agritepa, VII(2), 142-151.

Ma'ruf, MI., Kamaruddin, CA., dan Muharief, A., 2019. Analisis Pendapatan dan Kelayakan Usahatani Padi di Kecamatan Pitu Riawa Kabupaten Sidrap. Jurnal Sosial Ekonomi Pertanian, 15(3), 193-204.

Mawardi, NK., Ratri, WS., dan Widiatmi, S., 2020. Analisis Kelayakan Usahatani Padi di Lahan Pertanian SawahTadah Hujan di Desa Girikarto, Kecamatan Panggang, 
Kabupaten Gunungkidul. Jurnal Pertanian Agros, 22(2), 205-210.

Nasution, D., dan Rosmawati, H., 2018. Analisis Resiko Pendapatan Usahatani Bawang Merah di Desa Tungku Jaya Kecamatan Sosoh Buay Rayap Kabupaten Ogan Komering Ulu. Jurnal Agribisnis dan Sosial Ekonomi Pertanian (JASEP), 4(2), 24-30.

Nurhapsa, Kartini, dan Arham, 2015. Analisis Pendapatan dan Kelayakan Usahatani Bawang Merah di Kecamatan Anggeraja Kabupaten Enrekang. Jurnal Galung Tropika, 4(3), 137-143.

Sadaruddin, W., Baruwadi, M., dan Murtisari, A., 2017. Analisis Pendapatan Usahatani Bawang Merah di Desa Lenyek Kecamatan Luwuk Utara Kabupaten Banggai. Jurnal Agrinesia, 2(1), 17-26.
Sinaga, A., Rajab, A., Suddin, AF., Salaim, dan Amisnaipa, 2021. Peningkatan Produksi Melalui Penggunaan Varietas Unggul Barupada Usahatani Bawang Merah. Pangan, 30(1), 45-52.

Sugianto, S., Kurniawan, HM., dan Yuliarto, RT., 2019. Analisis Kelayakan Usahatani Bawang Merah di Kecamatan Rasau Jaya Kabupaten Kubu Raya. E-Jurnal Equilibrium Manajemen, 2(1), 8-12

Swastika, K., Ambarawati, IGAA., dan Dewi, IAL., 2017. Perbandingan Pendapatan Usahatani Bawang Merah dengan dan Tanpa Teknologi Feromon (Studi Kasus di Gapoktan Asta Mandiri, Desa Songan B, Kecamatan Kintamani, Kabupaten Bangli). E-Jurnal Agribisnis dan Agrowisata, 6(1), 76-85. 